\title{
The Joint Dynamics of Stock and Bond Risk-Returns in Japan
}

\author{
Changmin LeE ${ }^{*}$ AND HyOUNG-GOO KANG ${ }^{* *}$
}

\begin{abstract}
We examine the joint dynamics of stocks and bonds in the Japanese market by computing the prices of risks and their relationship in stock and bond factors. We deconstruct market factors into industry factors and incorporate bond factors such as the level, slope, and curvature of yield curves. This paper contributes to the literature by identifying the risk-return relationship in Japanese financial market and explaining the cross-sectional variations of stock returns in consideration of the bond market, and illustrating the importance of macro information in stock returns. Our approach and results provide practical implications to hedge fund managers, mutual fund managers, and basket traders.
\end{abstract}

Keywords: Stock Bond Joint Dynamics, Japanese Stock Market, Risk Return Tradeoff, Stock Risk Factors, Bond Risk Factors

Samsung Research Institure of Finance, Taepyoungro Bldg 14th Fl, Taepyoungro $2 \mathrm{Ga}$, Jung-gu, Seoul, Korea, 100-767: Tel: +82.2.3706-7473; E-mail: changmin0211.lee@samsung.net

Corresponding author. Hanyang University School of Business, 17 Haengdang-dong, Seongdong-gu, Seoul, Korea 133-791; tel; +82.2.2220-2883; E-mail: hyoungkang@hanyang.ac.kr 


\section{INTRODUCTION}

$\mathrm{T}$ he joint dynamics of stocks and bonds have become an increasingly important issue to financial managers. For example, portable alpha strategies became an influential investment practice in which bond managers imported alpha portfolios generated from equity strategies in order to enhance their bond portfolios. Equity portable alpha strategies generate superior returns based on the skill and knowledge of equity managers and strategists. If such portable alpha strategies work well, bond managers can combine the strengths of stock and equity portfolios. More importantly, portable alpha strategies allow combining the skills of talented fund managers in different asset classes. Nevertheless, it is significant to understand the joint dynamics of stocks and bonds in order to implement portable alpha strategies. More generally, the investment in more than one asset classes requires capturing the joint dynamics among asset classes. For the usefulness of portable alpha strategies and its relationship with stock bond joint dynamics, refer to Arnott (2002), Kung (2004), Fung (2004), and Ezrati (2006).

Existing literature agrees on the importance of joint dynamics. For example, Bekaert, Engstrom, and Grenadier (2010) model the dynamics of stocks and bonds in general equilibrium and show that such an approach can address important issues in finance. Nevertheless, it has been rarely investigated how well-known bond factors and sectoral portfolios jointly move. In addition, no paper analyzes the joint dynamics of stocks and bonds in the Japanese market. Given the large public debt, it becomes more important to analyze the dynamics of Japanese Government Bonds (JGB) and especially its implication to the stock market. Therefore, in this paper, we examine the joint dynamics of stocks and bonds at the level of sectoral factors and well-known bond factors in the Japanese market.

We offer several contributions in this paper. First, this paper resolves the disputes about expected return and risk relationships at the sectoral level. A large part of the current literature exists to investigate how market return and aggregate stock market volatility co-vary, but has generated conflicting results. We extend the method of Brandt and Wang (2010) to exploit cross-sectional information and find that risk-return relationship fluctuates significantly across industries. This is our contribution since no paper has analyzed the risk return relationship on a sectoral level or the joint dynamics of stocks and bonds. Given our results, it is not surprising that the existing literature produces conflicting results-the existing literature has not investigated the risk-return relationship on a sectoral level, but examined it only on an aggregate level. In addition, we use bond markets and macro information and identify the risk-return relationship in bond markets to extend existing literature.

Second, this paper uses bond market information and shows that the joint dynamics of stocks and bonds are important in asset pricing. Numerous papers 
argue the benefit of examining the joint dynamics of stocks and bonds such as Bekaert and Grenadier (1999), Mamaysky (2002), Wachter (2002), Brandt and Wang (2003), Dai (2003), Bekaert, Engstrom and Grenadier (2010). This paper is different from the existing literature in explaining cross-sectional variations of stock returns as well, which existing literature about joint dynamics have ignored.

Third, we model the stochastic discount factor, which can be easily transformed into a general equilibrium setting. Popular term structure models have presumed latent factors that do not directly present economic interpretations. In ad-hoc ways, they have regressed extracted latent factors on observable variables to draw intuitions. Some recent papers incorporate macro factors in term structure models. They are Wu (2002), Rudebusch and Wu (2008), and Hordahl, Tristani and Vestin (2006), Ang and Piazzesi (2003), Diebold, Rudebusch and Aruoba (2006). Nevertheless, neither the joint dynamics of stocks and bonds investigate these papers. Hollifield, Gallmeyer, and Zin (2005) intend to calibrate the McCallum rule and Taylor rule simultaneously using the CRRA (constant relative risk aversion) utility and numerical analysis, but they do not jointly investigate stock markets either. In contrast, we develop the model of joint stock-bond dynamics to generate clear economic interpretations.

This paper offers practical value to mutual fund managers, hedge funds, risk managers, and basket traders who should trade large portfolios. First, mutual fund managers can identify equilibrium risk premium which is useful as Black and Litterman (1992) illustrate. The equilibrium risk premiums are direct outputs of our model. In addition, since this paper analyzes the joint dynamics of stocks and bonds, it offers important implications to balanced funds and $401(\mathrm{k})$ plans which invest in stocks, bonds, and money markets. Second, our model can be useful to hedge fund managers and traders. As the corporate and credit derivatives market becomes liquid, both capital structure arbitrage and debt-equity relative value trading become more active. Hedge funds are one of the largest players in the market. The equilibrium stock and bond prices will be useful benchmarks to locate trading opportunities. In addition, the arbitrageurs can compute better hedge ratios between bonds and equities using our results about the co-movement and its implication to expected returns. Third, risk managers can identify the risks and prices especially in relation to industry factors. It will make risk management easier because widely available are the industry indices and tradable industry portfolios such as exchange traded fund (ETF). Furthermore, the risk and return trade-offs at the industry level will help the managers to classify risks into either hedging or taking. Fourth, basket traders can trade industry portfolios with ideas about how their transaction will jointly affect the expected return and risk so as to come up with better hedging strategies. In addition, the traders can relate the information contained in the yield curve with their trading strategies. 


\section{MODEL}

Let us denote a stock is total return between $t$ and $t+d t$ as $\left(P_{\mathrm{i} j+d t}+D_{\mathrm{i} f+d t}\right) / P_{\mathrm{it}}$ $\equiv R_{\text {it }}$. Presuming no arbitrage, we have a positive stochastic discounting factor $M$ such that:

$$
\begin{aligned}
& \mathrm{E}_{\mathrm{t}}\left(M_{t+d t} R_{t, t+d t}\right)=1 \text { and } \\
& \mathrm{E}_{\mathrm{t}}\left(M_{t+d t}\right)=\mathrm{P}(t, t+d t) \text { for all } t \text { and } t .
\end{aligned}
$$

$P(t, \tau)$ is the price of a pure discount bond at time $t$ maturing at $\tau$. Let us specify the stochastic discounting factor $(M)$ as

$$
M_{t+d t} \equiv \exp \left(-r_{/ t} \mathrm{dt}-\lambda_{t}^{T} d x_{t^{-}} \cdot 5 \sigma_{\mathrm{tu} t^{2}} \mathrm{dt}\right) .
$$

$d x_{i}$ is a column vector of stochastic mean-zero factor processes, and $\sigma_{\mathrm{Lu}}{ }^{2}=$ $\lambda_{t}^{T} \Omega_{t} \lambda_{t}$ in which $\Omega_{\lambda t}$ is factor-covariance matrix. We can interpret $\lambda_{t}$ as the price of risk associated with $d x_{t}$. If $d x$ are independent, $\lambda$, denotes the price of i.i.d shock to $d x$. The factors in $d x$ include stock market factors such as industry portfolio returns and market-dividend yield, and bond market factors such as default spread, risk-free rate, slope and curvature of yield curve. Those are the candidates of systematic factors. The bond market factors are important because future returns are found to be correlated with the factors (Ang and Bakaert 2007). With this specification, any expected stock return is given by

$$
\mathrm{E}_{\mathrm{t}}\left(R_{t, t+d t}\right)=\lambda_{\mathrm{t}}^{\mathrm{T}} \operatorname{cov}\left(d x_{\mathrm{t}}, R_{t, t+d t}\right)
$$

In particular, suppose $\mathrm{R}_{i, t+d t}$ is the return from an industry portfolio. Since $d x_{\mathrm{t}}$ includes industry returns, we can express the industry-portfolio return as the function of its variance and the covariance with other industries and factors as,

$$
\mathrm{E}_{\mathrm{t}}\left(R_{i n d . t+d t}\right)=\lambda_{\text {ind.t }} \operatorname{var}\left(R_{i n d, t+d t}\right)+\lambda_{\mathrm{t}}^{\mathrm{T}} \operatorname{cov}\left(d x_{\mathrm{t}}, R_{i, t+d t}\right) .
$$

In this framework, $\lambda_{\text {ind }}$ specifies risk-return relationship of an industry. Suppose we are only interested in the time-average/unconditional estimates of the risk-return dynamics parameters $\left\{\lambda_{t}, \sigma_{t, r^{2}}\right\}$. Let us denote them as $\left\{\lambda, \sigma_{t x}{ }^{2}\right\}$ to obtain serial average. Using law of iterative expectation, we can estimate them with the following generalized method of moments (GMM) equation,

$$
\mathrm{E}\left\{M_{t+d t}\left(R_{i, s+d t}, 1\right)\right\}=(l, P(t, t+d t)) .
$$

$\left(R_{i, t+d t}, l\right)$ is the $1 \times 2$ vector composed of a stock return and one. (1, $P(t$. 
$t+d t)$ ) is the $1 \times 2$ vector composed of one and the price (at time $t$ ) of pure discount bond maturing at $t+d t$. This set-up is convenient because we can bypass estimating $\operatorname{cov}\left(d x_{t}, R_{t, t+d t}\right)$ which requires further assumptions and of which specification very much influences the parameter estimates $\left\{\lambda, \sigma_{i x}{ }^{2}\right\}$ (Brandt and Wang, 2010).

\section{EMPIRICAL RESULTS}

We downloaded stock returns of all firms in the Tokyo Stock Exchange at monthly frequency from November 1989 to August 2006. The data source is Toyo Keizai and gives 4,753 firms. Then, we deleted 3,164 firms which did not furnish complete information. Bond information and other macro data are from Bloomberg and http://www.stat.go.jp.

The Tokyo Interbank Offered Rate (TIBOR) substitutes the short term bond yields, and swap rates substitute the bond yields with more than one year maturity. We use three-month TIBOR as the risk-free rate. The yield curve slope is the difference between three-month TIBOR and a 10-year swap rate. The yield curve curvature is (10-year swap rate $)+(3$-month TIBOR)- $2 *(5$-year swap rate).

We form an industry portfolio based on NEW FTSE/DJ INDUSTRY CLASSIFICATION BENCHMARK (ICB) standards and use equal weights. ICB Structure \& Codes are downloadable at http://www.icbenchmark.com/. Dow Jones Indexes and FTSE jointly provide such classification.

We use Markov Chain Monte Carlo (MCMC) methods in order to estimate the parameters in the GMM equations. The benefit of such methods is well explained in Chernozhukov and Hong (2003). For example, the estimation strategy is immune from the computational curse of dimensionality, but as efficient as extremum estimates, and performs well in finite samples. In addition, it has the advantage in dealing with latent factors. For example, it is easier to deal with the unobservable consumption processes relevant to asset pricing. People tend to use GDP or consumer expenses in nondurable goods to measure the consumption. However, they are only remotely related with the actual consumption that determines the marginal rate of substitution of a representative agent. The correct consumption should include the service flows from durable goods, which is very hard to estimate. In order to extract the proper consumption process from the observable, we need to do filtering, which the use of MCMC can facilitate.

Table 1 presents the posteriors of the risk-retum relation assuming the parameters are time invariant. It showcases several important findings. The estimates clearly show that the risk-return relation differs significantly across industries. Positive prices emerge for the risks in consumer services, industry, technology, and utilities. Negative prices are for factors relating to basic materials, consumer goods, and 
telecommunications. Neutral factors are financial, health care, and oil and gas. Our results strongly argue that it is misleading to aggregate those sectoral variations into a market portfolio in order to estimate the market price of risks. Depending on sectoral dynamics, we can have different market prices at aggregate levels. In view of our results, it is not surprising that the existing literature has produced conflicting results.

\section{Tabi.e 1. Posterior Distribution of the Time-Invariant Prices of Risks}

Table I shows the estimates of the parameters in the stochastic discounting factor when the parameters are assumed to be time-invariant. Stochastic discounting factor is $M_{t+d} \equiv \exp \left(-r_{t} d t-\lambda_{t}{ }^{7} d x_{r}-5 \sigma_{2,2}{ }^{2} d t\right)$. The items from Yield Curve Slope to Utilities signify the information about the posterior of $\lambda$. $\log$ (variance) term does the posterior about $\log \left(\sigma_{x}\right)$. We put * when the posterior mean is outside of two standard deviation from zero. We set the starting values as the classical GMM estimates with identity weighting matrix and do random walk sampling from standard multivariate normal. To derive the covariance matrices for the GMM equations, we use Bartlett kernel with lag 4. Simulation size is 500,000 .

\begin{tabular}{lccccc}
\hline & means & std.dev & skewness & kurtosis & \\
\hline Yield Curve Slope & 16.242 & 3.479 & -0.371 & 0.133 & $*$ \\
Yield Curve Curvarure & -5.968 & 1.032 & 2.259 & 7.323 & $*$ \\
Basic Materials & -4.581 & 0.683 & 0.894 & 0.668 & $*$ \\
Consumer Goods & -2.552 & 0.943 & 0.384 & -1.164 & $*$ \\
Consumer Services & 4.476 & 1.450 & -0.309 & -1.695 & $*$ \\
Financials & 0.441 & 0.347 & 0.656 & 4.130 & $*$ \\
Health Care & -0.666 & 1.058 & -0.373 & -0.691 & $*$ \\
Industrials & 1.160 & 0.495 & 0.191 & -0.363 & $*$ \\
Oil and Gas & 1.806 & 1.000 & -1.670 & 3.951 & $*$ \\
Technology & 8.126 & 1.244 & 0.120 & -1.246 & $*$ \\
Telecommunications & -7.105 & 0.768 & 1.107 & 3.7 .7 & $*$ \\
Urilities & 3.327 & 0.681 & -0.733 & -0.353 & $*$ \\
Log (variance) & -24.002 & 1.041 & 1.000 & 0.064 & $*$ \\
\hline
\end{tabular}

In addition, to exploit our specification $\mathrm{E}_{\mathrm{t}}\left(R_{\text {ind } d t+d t}\right)=\lambda_{\text {ind.t }} \operatorname{var}\left(R_{\text {ind } t+d t}\right)+\lambda_{t}^{\mathrm{T}}$ $\operatorname{cov}\left(d x_{i}, R_{i, s+d t}\right)$, we have the following implications. The higher the volatilities become, the higher the expected returns of consumer services, industry, technology, and utilities. The expected returns of basic materials, consumer goods, and telecommunications decrease with the increase of their variances. The existing literature is inconclusive about the sign of the relation, which we can explain as thus: earlier studies show either positive or negative relation depending on the specifications they employ. We conclude the disregard on the industry variation may cause the lack of definite answers in the prior literature.

In addition, the yield curve information is significant, which proves the importance of the joint dynamics of stocks and bonds in asset pricing. Stock returns are positively correlated with yield curve slope, but negatively with yield curve curvature. Skewness and kurtosis show the posteriors are far from normal. 


\section{CONCLUSION}

We compute the market prices of risk explicitly considering both stock and bond markets. We model the pricing kernel as the function of bond and industry factors. We can price individual assets applying our pricing kernel in order to assess over or under valuation. Therefore, our model has large implications to mutual fund managers, hedge funds, and risk managers. In addition, we can clearly show how macroeconomic factors such as interest rate variables can influence stock returns.

We applied our model to the Japanese market. We find that Japanese financial market prices industry factors as follows: consumer services, industry, technology, and utilities are positively priced, but basic materials, consumer goods, and telecommunications are negatively priced. Interestingly, the financial, health care, and oil and gas sectors are not significantly priced. Our results strongly demonstrate the misspecifications in the existing literature to investigate risk-return relationships. We argue that the conflicting results in the existing literature simply come from aggregating sectoral differences in misleading manners.

Future research can extend this paper in many ways. First, it can analyze individual stock and bond returns beyond portfolio returns. It can investigate alternative investments such as commodities, real estate, private equities, and hedge funds. Second, it can apply our framework to other financial markets. It can be interesting to analyze the joint dynamics of stocks and bonds in the global markets. Finally, it is straightforward to extend this approach to general equilibrium models. For example, we can simply change the stochastic discounting factor in our paper into the marginal rate of substitution over inter-temporal consumption. Given our exponential specification of the stochastic discounting factor, we can model exponential utility with the normal stochastic process.

\section{REFERENCES}

Ang, A. and G. Bakaert. 2007. Stock return predictability: Is it there? Review of Financial Studies 20(3): 651-707.

Ang, A. and M. Piazzesi. 2003. A No-Arbitrage Vector Autoregression of Term Structure Dynamics with Macroeconomic and Latent Variables. Journal of Monetary Economics 50(4): 745-787.

Arnott, R. D. 2002. Risk Budgeting and Portable Alpha. The Joumal of Investing 11(2): 15-22.

Bekaert, G., E. Engstrom, and S. R. Grenadier. 2010. Stock and bond returns with moody investors. Journal of Empirical Finance 17(5): 867-894.

Bekaert, G. and S.R. Grenadier. 1999. Stock and Bond Pricing in an Affine Economy. NBER Working Paper No. W7346. 
Black, F., and R. Litterman. 1992. Global Portfolio Optimization. Financial Analyst Journal 48(5): 28-43.

Brandt, M. W. and K. Q. Wang. 2003. Time-Varying Risk Aversion and Unexpected Inflation. Journal of Monetary Economics 50(7): 1457-1498.

Brandt, M. W. and L. Wang. 2010. Measuring the Time-Varying Risk-Retum Relation from the Cross-Section of Equity Returns. Duke University.

Chernozhukov, V. and H. Hong. 2003. A MCMC approach to classical estimation. Journal of Econometrics 115(2): 293-346.

Dai, Q. 2003. Term Structure Dynamics in a Model with Stochastic Internal Habit. Working Paper.

Diebold, F. X., G. D. Rudebusch, and S.B. Aruoba. 2006. The Macroeconomy and the Yield Curve. Journal of Econometrics 131(1-2): 309-338.

Ezrati, M. 2006. Portable Alpha: A Glimpse at the Future. The Journal of Investing 15(3): 119-123.

Fung, W, and D. A. Hsich. 2004. Extracting portable alphas from equity long-short hedge funds. Jotrnal of Investment Management 2(4): 1-19.

Hollifield, B., M. F. Gallmeyer, and S, E. Zin, 2005. Taylor Rules, McCallum Rules and the Term Structure of Interest Rates. Journal of Mlonetay Economics 52(5): $921-950$.

Hordahl, P., O. Tristani, and D. Vestin. 2006. A Joint Econometric Model of Macroeconomic and Term Structure Dynamics. Joumal of Econometrics 131(1-2): 405-444.

Kung, E. and L. Pohlman. 2004. Portable Alpha. The Journal of Portfolio Mamagement 30(3): 78-87.

Mamaysky, H. 2002. A model for pricing stocks and bonds. International Center for Finance, Yale University.

Rudebusch, G. D. and T. Wu. 2008. A Macro-Finance Model of the Term Structure, Monetary Policy, and the Economy. The Economic Journal 118(530): 906-926. Wachter, J. 2002. Habit Formation and Returns on Stocks and Bonds. Working Paper. New York: New York University.

Wu, T. 2002. Monetary Policy and the Slope Factors in Empirical Term Structure Estimations, Working Paper 2002-07. Federal Reserve Bank of San Francisco. 